\title{
Management of Metabolic Acidosis in Acute Gastro-enteritis
}

\author{
H. DE V. HEESE,* M.D., B.SC., M.R.C.P.ED., D.C.H. ; C. TONIN,* M.B., CH.B. \\ M. D. BOWIE,* M.B., B.SC., M.R.C.P.ED., D.C.H. ; A. EVANS,* B.SC.
}

Brit. med. F., 1966, 2, 144-146

The management of gastro-enteritis with dehydration and electrolyte and acid-base disturbances presents one of the commonest clinical problems in hospital paediatric practice in Capetown. A large proportion of the 150,000 attendances at the outpatient department of the Red Cross War Memorial Children's Hospital are concerned with gastro-enteritis. During the summer months up to 90 or more dehydrated infants a day receive intravenous fluid therapy in the "drip-room." Un!er these conditions it is not possible or practicable to correct biochemical derangements in each infant individually under laboratory control. Schemes of management have had to be devised which could deal with the majority of cases satisfactorily. Biochemical control could then be reserved for severely ill infants or those who failed to respond to the standard regimen.

The use of half-strength Darrow's $-2.5 \%$ dextrose as a standard solution for intravenous therapy in all cases of gastroenteritis managed in the drip-room has proved to be simple and effective. It is unassociated with possible iatrogenic electrolyte or other disturbances (Hansen, 1957 ; Bowie, 1960 ; RainierPope, 1962).

This report deals with an assessment of $(a)$ the effectiveness of this standard regimen, and $(b)$ the possible beneficial effects of adding sodium bicarbonate to the above solution for the correction of the acid-base disturbances encountered in these infants.

All infants were excluded from the trial who were moribund on admission or had arterial $p \mathrm{H}$ values below 7 . In these infants the acidosis was rapidly corrected by intravenous $4 \%$ sodium bicarbonate solution followed by the Darrow's-dextrose solution with added sodium bicarbonate.

\section{Material and Methods}

Thirty infants with acute gastro-enteritis who showed clinical evidence of dehydration and acidosis were taken at random and divided into two equal groups. Their ages ranged from 2 to 18 months and their weights between 2.6 and $9.1 \mathrm{~kg}$. Their mean age was 6 months, and the mean weight approximately $70 \%$ of the expected weight. Many of these infants showed evidence of malnutrition.

Group I received standard intravenous therapy with halfstrength Darrow's- $2.5 \%$ dextrose solution. In group 2 cases $4 \%$ sodium bicarbonate was added to the standard solution in an amount calculated from the base excess and weight for each individual according to the formula: $\mathrm{mEq}$ sodium bicarbonate $=0.3 \times$ base excess $\times$ weight in $\mathrm{kg}$. (Mellemgaard and Astrup, 1960).

The amount of fluid administered intravenously via scalpvein infusion over the 24-hour period of study was calculated from the weight of the child and the degree of dehydration. The latter was assessed clinically as $5 \%$ or $10 \%$, because data on changes in weight were not usually available. The infant was regarded as being $5 \%$ dehydrated in the presence of signs such as dryness of the skin, mucous membranes, oliguria, and slight depression of the fontanelle. Moderate depression of the fontanelle and eyeballs, loss of elasticity and turgor of the abdominal skin, circulatory disturbance manifested by mottled skin, cool extremities, tachycardia, and severe oliguria were taken as signs of $10 \%$ dehydration.

The fluid deficit was correspondingly estimated at $50 \mathrm{ml}$. or $100 \mathrm{ml} . / \mathrm{kg}$. of body-weight for $5 \%$ and $10 \%$ dehydration respectively. A fifth of this deficit was given as rapidly as possible, within 15 to 30 minutes, and four-fifths over a period of four to five hours. In those who received $4 \%$ sodium bicarbonate a quarter of the calculated amount was given rapidly and the remainder over a period of four to five hours. In aduition, the maintenance fluid requirement of $150 \mathrm{ml} . / \mathrm{kg}$. of body-weight was administered over the remainder of the 24-hour period. The mother or father usually remained with the infant in the drip-room, and they were instructed to offer oral Darrow's solution with added potassium chloride ad lib. to the infant provided there was no persistent vomiting. The amount of fluid given orally in this manner proved adequate to cover further losses from diarrhoea and vomiting. The progress of all the infants was assessed frequently by us and the nursing staff in attendance.

Antibiotic therapy with either sulphadiazine or tetracycline was given routinely. All infants were weighed on admission and after 24 hours of intravenous therapy. After discharge of the infant from the drip-room the parents were instructed to continue with the antibiotic therapy and to administer Darrow's solution orally for a few hours longer and then recommence full-strength milk feeds. All children were seen on the day following discharge in order to assess maintenance of hydration, and again at intervals for a week or until the diarrhoea ceased.

\section{Biochemical Investigations}

A sample of heparinized blood was collected from the temporal artery under sterile and anaerobic conditions (Thomsen, 1964) in all infants before the beginning of treatment. The $p \mathrm{H} \mathrm{PCO}_{2}$, base excess, standard bicarbonate, actual bicarbonate, and buffer base were immediately measured at the bedside, and the serum $\mathrm{Na}^{+}, \mathrm{K}^{+}, \mathrm{Cl}^{-}, \mathrm{Ca}^{++}$, urea, and proteins were determined in the hospital biochemical laboratory. Intravenous therapy was then begun, and subsequent values for the $\mathrm{pH}$, $\mathrm{PCO}_{2}$, base excess, standard bicarbonate, actual bicarbonate, and buffer base were determined from capillary blood taken by stab of the adequately warmed heel (Siggaard Anderson et al., 1960 ; Gambino, 1961 ; Gandy et al., 1964). The first specimen from the warmed heel was taken 30 minutes after the beginning of therapy, and further capillary samples were collected at hourly intervals for the first five hours and then at longer intervals up to 24 hours. Approximately 10 determinations were carried out on each infant over the 24-hour period.

In 16 children blood was again taken from the temporal artery for electrolyte and acid-base determinations after 24 hours of therapy.

* Department of Paediatrics, Red Cross War Memorial Children's Hospital and Department of Child Health, University of Capetown. 
Temperature corrections were made for the actual $p \mathrm{H}$ measurements by adding a factor of 0.015 for every $1^{\circ} \mathrm{C}$. that the patient was below $38^{\circ} \mathrm{C}$. to the $p \mathrm{H}$ value measured at $38^{\circ} \mathrm{C}$. When the patient's temperature was over $38^{\circ} \mathrm{C}$. this factor was subtracted (Rosenthal, 1948 ; Siggaard Anderson, 1963).

\section{Results}

The two groups were comparable in all respects before treatment was started (Table I).

The correction of the metabolic acidosis occurred at a much faster rate in those who received sodium bicarbonate (Table II). In this group almost complete correction had taken place after 10 hours of therapy, whereas the group 1 patients who received no sodium bicarbonate still showed evidence of metabolic acidosis at this stage. After 24 hours of therapy, however, there was no difference between the two groups (Table II).
No case of tetany was observed in either of the groups, in spite of the rapid correction of the metabolic acidosis in some cases. Two of the 30 infants died. Both had received intravenous sodium bicarbonate, but death was probably unrelated to this therapy. The first infant suffered from kwashiorkor and died suddenly at the end of the 24-hour period of observation. Post-mortem examination showed features of kwashiorkor only. The second infant died after 14 hours of treatment. This infant was severely ill and comatosed on admission, with a temperature of $104^{\circ} \mathrm{F}$. $\left(40^{\circ}\right.$ C.), $15 \%$ dehydration, arterial $\mathrm{pH} 7.04$, base excess $-25 \mathrm{mEq} / 1$, $\mathrm{PCO}_{2} 16.3 \mathrm{~mm}$. $\mathrm{Hg}$, actual bicarbonate $4.5 \mathrm{mEq} / 1$, and serum sodium $162 \mathrm{mEq} / 1$.

During the follow-up period nine of the infants required further intravenous fluids for recurrence of dehydration within 72 hours of discharge. Four of these were from group 1 (without sodium bicarbonate) and five from group 2 (with sodium bicarbonate). In two infants in each group the recurrent dehydration was associated with a moderate metabolic acidosis. Recovery was uneventful in the other infants.

Table I.-Comparison of the Average Weights, Ages, and Serum Electrolytes in the Two Groups Prior to Therapy

\begin{tabular}{|c|c|c|c|c|c|c|c|c|}
\hline & & & & & & & & \\
\hline Infants & $\underset{\text { in }}{\text { Age }}$ & Weight & & $\mathrm{Na}^{+}$ & $\mathrm{Cl}^{-}$ & $\mathrm{K}^{+}$ & $\mathrm{Ca}^{++}$ & Urea \\
\hline & Months & (kg.) & (g./100 ml.) & & $\mathrm{mEq} / \mathrm{l}$ & & $\mathrm{mg} . / 1$ & $00 \mathrm{ml}$ \\
\hline $\begin{array}{l}\text { Group } \frac{1}{2} \text { (range) } \\
\eta\end{array}$ & $\begin{array}{l}5(2-12) \\
7(2-18)\end{array}$ & $\begin{array}{l}4 \cdot 8(2 \cdot 6-7 \cdot 2) \\
5 \cdot 3(3 \cdot 0-9 \cdot 1)\end{array}$ & $\begin{array}{l}6 \cdot 4(3.92-8 \cdot 29) \\
6 \cdot 4(5 \cdot 09-8 \cdot 10)\end{array}$ & $\begin{array}{l}140(113-162) \\
143(129-158)\end{array}$ & $\begin{array}{l}118(105-135) \\
115(103-133)\end{array}$ & $\begin{array}{l}3.9(2.3-5.4) \\
4.5(2.3-7.9)\end{array}$ & $\begin{array}{r}9 \cdot 8(8 \cdot 5-10 \cdot 9) \\
10 \cdot 5(9 \cdot 8-11 \cdot 0)\end{array}$ & $\begin{array}{l}45 \cdot 9(21 \cdot 6-99 \cdot 0) \\
64 \cdot 6(24 \cdot 3-195 \cdot 0)\end{array}$ \\
\hline
\end{tabular}

TABLE II.-Comparison of the Serial Acid-base Changes in the Two Groups After Therapy

\begin{tabular}{|c|c|c|c|c|c|c|}
\hline $\begin{array}{c}\text { Time } \\
\text { (hours) }\end{array}$ & Group & $p \mathrm{H}$ & $\begin{array}{c}\mathrm{PCO}_{2} \\
(\mathrm{~mm} . \mathrm{Hg}) \\
\end{array}$ & $\begin{array}{c}\text { Base Excess } \\
(\mathrm{mEq} / 1 .)\end{array}$ & $\begin{array}{c}\text { Actual Bicarbonate } \\
(\mathrm{mEq} / 1 .)\end{array}$ & $\begin{array}{l}\text { Blood } \\
\text { Sample }\end{array}$ \\
\hline $\begin{array}{c}0 \\
\frac{1}{2} \\
2 \frac{1}{2} \\
3 \frac{1}{2} \\
10 \\
22\end{array}$ & 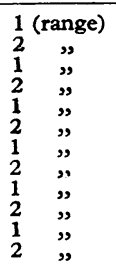 & $\begin{array}{l}7 \cdot 19(7 \cdot 05-7 \cdot 28) \\
7 \cdot 16(7 \cdot 00-7 \cdot 34) \\
7 \cdot 18(6 \cdot 97-7 \cdot 28) \\
7 \cdot 20(6 \cdot 90-7 \cdot 38) \\
7 \cdot 27(7 \cdot 12-7 \cdot 38) \\
7 \cdot 33(7 \cdot 15-7 \cdot 44) \\
7 \cdot 28(7 \cdot 16-7 \cdot 39) \\
7 \cdot 37(7 \cdot 22-7 \cdot 45) \\
7 \cdot 35(7 \cdot 20-7 \cdot 54) \\
7 \cdot 41(7 \cdot 20-7 \cdot 51) \\
7 \cdot 39(7 \cdot 28-7 \cdot 50) \\
7 \cdot 42(7 \cdot 34-7 \cdot 51)\end{array}$ & 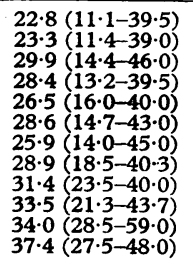 & $\begin{array}{l}-18 \cdot 2(-25 \cdot 0--8 \cdot 6) \\
-18 \cdot 8(-25 \cdot 0-7 \cdot 8) \\
-18 \cdot 0(-25 \cdot 0--8 \cdot 6) \\
-15 \cdot 6(-25 \cdot 0--3 \cdot 6) \\
-13 \cdot 3(-21 \cdot 0--7 \cdot 1) \\
-9 \cdot 3(-18 \cdot 7-+2 \cdot 0) \\
-12 \cdot 8(-21 \cdot 0--5 \cdot 0) \\
-7 \cdot 3(-18 \cdot 2-+4 \cdot 0) \\
-7 \cdot 48(-17 \cdot 0-+4 \cdot 0) \\
-2 \cdot 2(-17 \cdot 3-+6 \cdot 8) \\
-0 \cdot 3(-9 \cdot 3-+10 \cdot 0) \\
+0.6(-6 \cdot 5-+8 \cdot 0)\end{array}$ & $\begin{array}{r}8 \cdot 9(4 \cdot 5-17 \cdot 5) \\
8 \cdot 7(4 \cdot 5-18 \cdot 8) \\
9 \cdot 7(5 \cdot 6-17 \cdot 5) \\
11 \cdot 8(6 \cdot 4-20 \cdot 0) \\
12 \cdot 0(6 \cdot 4-18 \cdot 6) \\
15 \cdot 1(8 \cdot 8-25 \cdot 2) \\
12 \cdot 3(6 \cdot 4-20 \cdot 8) \\
16 \cdot 4(8 \cdot 3-27 \cdot 4) \\
16 \cdot 8(4 \cdot 8-24 \cdot 0) \\
18 \cdot 5(9 \cdot 5-30 \cdot 0) \\
24 \cdot 0(15 \cdot 0-36 \cdot 0) \\
23 \cdot 8(17 \cdot 5-31 \cdot 7)\end{array}$ & $\begin{array}{l}\text { Arterial } \\
\text { Arterialized } \\
\text { capillary } \\
\text { blood }\end{array}$ \\
\hline
\end{tabular}

A minority of infants in both groups showed biochemical evidence of mild metabolic alkalosis and overcorrection towards the end of the 24-hour period.

The differences between the two groups were less marked when assessed clinically, and evident only during the earlier stages of treatment. Earlier circulatory improvement, manifested by better colour, pulses, and flow of blood from the heel stab, was present in group 2 patients who had received intravenous sodium bicarbonate.

The effect on the increased sodium load on the serum sodium was assessed in seven patients who received sodium bicarbonate and compared with nine who had not received it. The preand post-24-hour therapy levels are compared in Table III. In group 1 two infants showed evidence of hypernatraemia (serum $\mathrm{Na}^{+}>150 \mathrm{mEq} / \mathrm{l}$.) before intravenous therapy but none afterwards.

TABLE III.-Serum Sodium Levels Before and After 24 Hours of Therapy

\begin{tabular}{c|c|c|c|c}
\multicolumn{2}{c|}{ Group 1 } & \multicolumn{3}{|c}{ Group 2 } \\
\hline $\begin{array}{c}\text { Initial } \\
\text { Serum Na+ } \\
(\mathrm{mEq})\end{array}$ & $\begin{array}{c}\text { Final } \\
\text { Serum Na } \\
(\mathrm{mEq})\end{array}$ & $\begin{array}{c}\text { Initial } \\
\text { Serum Na+ } \\
\text { (mEq) }\end{array}$ & $\begin{array}{c}\text { Final } \\
\text { Serum Na+ } \\
\text { (mEq) }\end{array}$ & $\begin{array}{c}\text { Sodium } \\
\text { Bicarbonate } \\
\text { Added (mEq) }\end{array}$ \\
\hline 142 & 140 & 144 & 162 & 42 \\
162 & 138 & 152 & 134 & 30 \\
154 & 144 & 137 & 135 & 12.5 \\
140 & 144 & 132 & 138 & 22.5 \\
113 & 130 & 148 & 160 & 38 \\
148 & 126 & 129 & 128 & 45 \\
136 & 138 & 158 & 148 & 8 \\
146 & 132 & 143 & 143 & \\
\hline Average 140 & 135.2 & 143 & &
\end{tabular}

\section{Discussion}

The present study confirms that in cases of severe gastroenteritis where dehydration is pronounced ( $10 \%$ or more) but the infant is not moribund, and provided the liver and kidneys are essentially normal, the metabolic acidosis can be corrected by applying the proved principles of fluid therapy. These include the administration to the infant of water and electrolyte in adequate but not excessive quantities to cover deficits, to maintain normal physiological requirements, and to replace any abnormal losses in the stools and vomitus. Under the conditions specified the present study substantiates the value in management of acute gastro-enteritis of administering halfstrength Darrow's- $2.5 \%$ dextrose solution in the volumes and at the rate of administration stated. In doing so it must be kept in mind that this solution contains lactate $26 \mathrm{mEq} / 1$. and is therefore mildly alkalinizing by virtue of its content of bicarbonate precursors.

Whether the slightly more rapid correction of the metabolic acidosis in the infants of group 2 was advantageous to them is debatable, but the evidence of any benefit is not impressive in the present series.

Those moribund severely dehydrated infants with arterial $p H$ values below 7 who were excluded from the present trial responded in a dramatic fashion, with improvement of colour, circulation, respiration, and level of consciousness, to intravenous $4 \%$ sodium bicarbonate followed by half-strength Darrow's $-2.5 \%$ dextrose solution with added sodium bicarbonate. There is therefore little doubt that the administration of alkalinizing agents such as sodium bicarbonate is indicated in these life-threatening situations or where severe diarrhoea 
(and continued loss of alkali) persists and the degree of metabolic acidosis becomes more pronounced or remains static.

In the present study, although marked circulatory improvement took place during the first 30 minutes of rapid infusion of fluids, the first acid-base values obtained from the warmed heel-capillary blood should probably be interpreted with reservations. The infants who received sodium bicarbonate had a much freer flow of blood, and the magnitude of the difference in the acid-base values between the two groups after 30 minutes of therapy may perhaps be partly explained on this basis. For the same reason little comment can be made on the correction patterns of the metabolic acidosis in the two groups. This fascinating aspect must await further study.

The question arises whether the empirical administration of sodium bicarbonate in the specified amounts can be harmful. Some of the petential hazards are: (1) the danger of inducing or aggravating hypernatraemia, which is a well-recognized complication of gastro-enteritis with dehydration (Bowie et al., 1958); (2) the danger of inducing tetany as a result of the too-rapid correction of the metabolic acidosis; and (3) the production of a significant metabolic alkalosis.

The last complication was not encountered in the present series or with the extensive use of sodium bicarbonate in the specified amounts in a large number of other cases of acute gastro-enteritis. Two of seven children who received sodium bicarbonate developed asymptomatic hypernatraemia, but two who had hypernatraemia before therapy had normal sodium levels afterwards. A much larger trial will have to be carried out to determine the hazard of hypernatraemia.

None of the infants developed signs of tetany, though this complication has been encountered in dehydrated infants corrected with the routine solution alone or with added bicarbonate. Its occurrence seems to be largely unrelated to the speed of correction of the metabolic acidosis.

\section{Conclusions}

The formula employed for the calculation, from the initial base excess value, of the amount of bicarbonate to be administered with the standard solution proved adequate in most cases. In premature infants and neonates, with their larger extracellular fluid compartment, more sodium bicarbonate can be administered with safety according to the formula: $\mathrm{mEq}$ of sodium bicarbonate $=0.5 \times$ base excess $\times$ body-weight in $\mathrm{kg}$.

Investigations into the initial acid-base status of untreated cases of acute gastro-enteritis carried out over the last two years have indicated that approximately $10 \%$ dehydrated cases have base excess values of -15 to -20 , whereas severely dehydrated and moribund cases have base excess values of more than -25 to -30 . It is suggested that where facilities are not available to carry out arterial acid-base studies, and where it is thought necessary to administer sodium bicarbonate, the amount be calculated empirically on the following figures:

1. In $10 \%$-dehydrated infants a base excess value of -15 can be assumed. According to the formula $4.5 \mathrm{mEq} / \mathrm{kg}$. or $9 \mathrm{ml} . / \mathrm{kg}$. of $4 \%$ sodium bicarbonate can be administered to correct the deficit of base in the extracellular space.

2. In moribund severely dehydrated $(>15 \%)$ acidotic children, a base excess of -25 can be assumed and $7.5 \mathrm{mEq} / \mathrm{kg}$. or $15 \mathrm{ml} . / \mathrm{kg}$. of $4 \%$ sodium bicarbonate administered. A quarter of the calculated dose of bicarbonate is given rapidly, within 30 minutes, and the remainder over the next four to five hours.

\section{Summary}

The addition of bicarbonate to a standard regimen of intravenous half-strength Darrow's- $2.5 \%$ dextrose solution in the rehydration of children dehydrated and acidotic from gastroenteritis leads to a somewhat more rapid return to normal acid-base status. The standard regimen without additional bicarbonate returns the acid-base status to normality over a longer period. There is only minimal clinical evidence that the more rapid correction with bicarbonate is beneficial in infants approximately $10 \%$ dehydrated. In moribund severely dehydrated and acidotic infants the administration of sodium bicarbonate is not only indicated but may be life-saving.

An arterial puncture is necessary for the adequate biochemical evaluation of the acid-base status in dehydrated shocked children. In shocked infants it is impossible to obtain a free flow and a true arterialized blood sample by capillary puncture.

Bicarbonate therapy, based on the formula described, did not lead to significant metabolic alkalosis or tetany.

Hypernatraemia developed in two infants who received bicarbonate, and a larger study will be necessary to assess this potential danger.

A scheme is put forward for the empirical administration of sodium bicarbonate to severely ill infants with gastro-enteritis when time or facilities are not available for routine acid-base studies.

Thanks are due to Dr. F. J. W. Mostert, Medical Superintendent of the Red Cross War Memorial Children's Hospital, for permission to publish; to Professor F. J. Ford for facilities; to Dr. David McKenzie for the biochemical investigations; and to Mrs. O. M. Cartwright for her assistance in the preparation of the manuscript. We are indebted to the Staff Research Fund (Teaching Hospitals Board) for financial assistance.

\section{REFERENCES}

Bowie, M. D. (1960). S. Afr. med. 7., 34, 344.

McKenzie, D., and Hansen, J. D. (1958). Ibid., 32, 322.

Gambino, S. R. (1961). Amer. F. clin. Path., 35, 175.

Gandy, G., Grann, L., Cunningham, N., Adamsons, K., jun., and James, L. S. (1964). Pediatrics, 34, 192.

Hanse

Hansen, J. D. L. (1957). Strup, P. (1960). Scand. F. clin. Lab. Invest., 12,187 .

Rainier-Pope, C. R. (1962). S. Afr. med. f., 36, 1087.

Rosenthal, T. B. (1948). f. biol. Chem., 173, 25

Siggard Andersen, O (1963). Scand. F. clin. Lab. Invest., 15, Suppl No. 70.

- Engel, K., Jørgensen, K., and Astrup, P. (1960). Ibid., 12, 172.

Thomsen, A. (1964). Acta paediat. (Uppsala), 53, 237. 